\title{
How Polite You Are: A Study of Learners' Politeness Strategies Used in Avatars in the Second Life Virtual World
}

\author{
Ko, Ling-Yao \\ Division of English, Chang Gung University of Science and Technology \\ PhD. TESTOL Program, Department of English, Tamkang University \\ Taiwan \\ Ko, Ling-Yao \\ No. 261, Wenhua $1^{\text {st }} \mathrm{Rd}$ \\ Guishan Dist., Taoyuan City 33303 \\ Taiwan (R.O.C)
}

This study explores how politeness strategies are used through avatars in chat-based Second Life (SL) virtual worlds and how speech-act performance can be learned through the suggestions of experts to help enhance learners' pragmatic language acquisition. The study was based on a one-semester assignment which allowed students to bolster their university English-reading course grade through participation in the study.The total number of participants was 240, 50 Taiwanese nursing students and 190 non-Taiwanese Second Life players. The 50 students had studied English for at least four years, but their English proficiency level was below the passing threshold of the Elementary Level of the General English Proficiency Test(GEPT) in Taiwan. The 50 participants were requested to play an online game namedSecond Life and to chat online with no more than five foreigners randomly chosen by them. After the students played the game in the virtual world, text records of their online chatting were collected so as to analyze the politeness strategies used in SL. The results showed that the most common politeness strategy used was in a direct command (73.78\%); the second one, positive politeness (15.8\%); the third one, negative politeness (6.01\%); the fourth one, off record (3.4\%), the fifth one, pre-request $(0.77 \%)$, and the last one, bald on record (0\%). In order to improve the politeness strategies used on the internet, Speech acts related to politeness in traditional and nontraditional learning context would be recommended in this paper as well.

Keywords: politeness strategies, Second Life, virtual online world, avatars, speech acts

\section{Introduction}

With the rapid advancement of technology, computer-mediated communication (CMC) has developed into a worldwide medium of communication. The term CMC, coined by Hiltz and Turoff (1993), refers to a mode of electronic communication engaged in through e-mail, bulletin boards, Internet Relay Chat (IRC), chat rooms, and the World Wide Web. CMC is often touted as a way to build and promote interpersonal and social relationships; however, inappropriate online behaviors may put users in an uncomfortable or even dangerous position. Some people on the internet freely say what they want to say and do what they want to do while using communication tools. Therefore, the application of politeness strategies on the internet is an important issue to discuss.

Unlike animals, humans use spoken and written language to communicate with each other. Through language, humans make their demands known to others, express their feelings and opinions on various issues, and negotiate with others. The process of communication is an essential part of human life because human society requires personal interactions(Song, 2012). It is important to consider someone's attitude when they are doing or saying something because what they say and what they communicate is determined by their social relationships. According to Yule(1997), a linguistic interaction is actually a social interaction. Various factors will have a great impact on social interaction, such as social distance and closeness, age, power, social values, and the degree of friendliness/politeness imposed into interaction.

\section{Literature Review}


Politeness is considered as a "polite social behavior, or etiquette, within a culture"(Yule, 1997, p.60). Some principles about being polite in social interaction include being tactful, generous, modest and sympathetic toward others (Yule, 1997). Politeness is a universal phenomenon that shows one has good manners and consideration for other people(Yule,1997). Tolmach(1990) defines politeness as a system of interpersonal relations designed to facilitate interaction by decreasing the conflict and confrontation innate in all human interchanges. These definitions of politeness have the element in common of avoiding conflicts with others. Thus, we can assume that politeness involves speaker's intention not to offend the listener when interacting. Since politeness is a critical concept in interpersonal communication, there are numerous studies which explore it. According to Watts(2003), polite behavior is a refined behavior that relies on social conventions, which are socially regularized and evaluated. Its main functions are keeping a cooperative social interaction and avoiding unnecessary conflicts. In other words, politeness works to maintain the social status quo and avoid devaluation of others. Goffman(1955) defines politeness as the actions of a person who is pledged to protect both his own "face" and the "faces" of others in social interaction. Adopting Goffman's notion of the social self, Levinson, \& Levinson(1987, p.61) define face as " the public self-image that every member wants to claim for himself/herself". Both Goffman's and Brown and Levinson's views argue that face is something to be established, maintained, improved, disjointed, and rebuilt in social interactions. In other words, faces are kind of elucidation or reputation that people want for themselves in terms of others' views of them. The concept of face in East Asia is somewhat different from that in American cultures because it contains an element of group-identity (Song, 2012). Ukosakul (2005, p. 119) defines face as a term which includes "personality, emotions, honor, self-esteem, prestige, reputation and price". Wakimae defines face in Japan as 'one's sense of self and relation to others"(recited from Ide, 2005). Regardless of the minor cultural variations of face, the concept of face as a social self in a given culture provides the basis for most politeness theories. In this study, we will discuss how often the Taiwanese study subjects and the people from other countries with whom they communicate online make use of politeness strategies to save their and others' face. Furthermore, we will provide some ways to enhance the learners' pragmatic acquisition of English.

\section{Definition of Politeness Strategies}

Politeness, in an interaction, can be defined as the means employed to show awareness of another person's face, which means the public self-image of a person (Yule, 1997). Politeness is the expression of the speaker's intention to mitigate face-threats carried by face-threatening acts toward others. If people are not aware of their attitudes while they are doing or saying something, they might not be careful about the words or the communication methods they use during their conversation. It will probably result in misunderstanding between the listener and speaker. That is to say, it might give a bad impression or harm the relationship between the listener and speaker. The interactions that foster interpersonal conflict are labeled "face-threatening acts "(FTAs). Examples of FTAs that occur in social interaction include acts of impugning, criticizing, disagreeing, obstructing, commanding, borrowing, asking a favor, seeking information, or disturbing. Briefly, politeness is the way to avoid any misunderstandings or FTAs, to build a good relationship and also to have a good social interaction with other people. Brown and Levinson's politeness theories are similar to those of Dell Hyme's. Hyme(1967) proposed the notion of communicative competence, which refers to the knowledge that we need to use in a social context. Hyme termed this approach as "the ethnography of speaking". He created the acronym SPEAKING, which stands for setting and scene, participants, ends, act sequence, key, instrumentalities, norms, and genre. The SPEAKING model is a tool to assist in the identification of the various linguistic interaction in certain situation. In order to speak a language properly, one needs not only to learn its vocabulary and grammar but also the context in which the words and grammar should be used. Using the SPEAKING model is a way to help linguistic competence. Similarly, Brown and Levinson proposed that politeness is a way to mitigate face threats carried by certain face-threatening acts toward the listeners. Therefore, being polite can be an attempt for the speaker to save their won face or the face of the other to whom he or she is talking.

According to Levinson et al(1987), there are different kinds of politeness strategies. Off Record refers to the strategy of using a hint to get one's needs recognized. For example, when someone says that he forgot his pen or he has no idea where he put his pen, we know that he wants someone else to lend him a pen. Bald on Record is the strategy of directly expressing one's needs by giving a direct command or perform the direct command with imperative ways. For example, someone might way, "Give me a pen", or "Lend me your pen", when in need of a writing instrument. The Bald on Record strategy may include words and phrases such as "please" and "would you?" which serve to soften the demand. 
These are called mitigating devices. Generally speaking, Bald on Record expressions are associated with speech events in which the speaker assume that he/she has power over the other and can control the other's behavior with words. In everyday interaction, such Bald on Record behavior have a high likelihood of threatening the other's face and should generally be avoided. Direct Command is easily confused with Bald on Record because imperative forms are often used by those in a close relationship without being interpreted as commands, such as when someone says to another, "Have some more cake", or "Give me that wet umbrella".

Avoiding a face-threatening act can also be accomplished by using the Positive Politeness strategy or the Negative Politeness strategy. A speaker can use the Positive Politeness strategy to appeal to a friendship via polite expressions. The speaker can say something like, "I'd appreciate it if you'd let me use your pen", to achieve his goal of borrowing the pen from someone. However, according to Yule (1997), a face-saving act is more commonly performed via the Negative Politeness strategy because the Negative Politeness strategy is typically expressed via questions that seem to ask for permission. The speaker says something like, "I'm sorry to bother you, but can I ask you for a pen?" The tendency to use positive politeness forms is to emphasize the closeness between the speaker and hearer, and it can be considered a solidarity strategy. Frequently, a solidarity strategy will be marked via terms such as "we" and "let's". The tendency to use the Negative Politeness strategy is to emphasize the listener's right to freedom, and it can be considered a deference strategy. A deference strategy is involved in what is called "formal politeness"(Yule, 1997). The language associated with deference strategies emphasizes the speaker's and listener's independence. As already suggested, the concept of face-saving may be helpful in understanding how participants in an interaction comprehend more than just what is said.

From the perspective of politeness, the way to avoid face-threatening acts can be also through the method of PreRequest, which can be answered either with a "go-ahead" or "stop" response. A question utilizing the Pre-Request strategy, such as "Are you busy?" can be answered with a go-ahead response ("Not really.") or a stop response ("Sorry, I'm a little busy right now.")

\section{The Online World of Second Life}

Second Life (SL) is an online virtual world developed by Linden Lab. It is a free 3D virtual world where users can socialize, connect, and create using free voice and text chat. Second Life users are able to interact with each other through avatars, also known as residents. Residents can explore the world, meet other residents, socialize, participate in individual and group activities, and create and trade virtual property and services with one another. If the Second Life users get tired of their current avatars, they are allowed to change into another avatar, such as a human, animal, vampire, robot, or car. In Second Life, you live in a new body, taking on the identity of your "avatar" that is, a being you have created as a representation of yourself in this online environment. The avatars can walk, run or fly in the Second Life, never getting drowned in the sea, nor will they fall to the ground with serious injuries. Avatars are endowed with mannerisms, skills, and wardrobes that have been created by their users.

Studies related to the virtual online world and politeness strategies are quite few. Peterson (2006) conducted a research study on learner participation patterns and strategies used in the online world. His research was a case study that investigated the interaction of intermediate-level EFL learners in Second Life. Analysis of the data revealed that the context and tasks that appeared in SL drew forth a high degree of participation. The interaction was highly learner-centered, because there were the majority of messages exchanged among learners. The analysis further indicated that the subjects could produce coherent target language while they focused on the tasks through collaborative interaction. Winerta \& Hamzah(2012) analyzed the politeness strategies used in human and avatar-based conversations in the science-fiction movie Avatar. The reason why the researcher chose the Avatar movie to analyze was that it contained many politeness strategies. The researcher did the research based on two theories: one based on Brown and Levinson's theory, which refers to politeness as the expression of the speaker' intention to mitigate face-threats carried by certain face threatening acts toward another, and the other based on Hyme's SPEAKING theory, with the intention to analyze the context of request strategies occurring in the conversation among the characters. The researcher compared the politeness strategies used by the real humans and the transfer-humans (avatars). Pearson (2006) conducted research on learner-interaction management in an avatar and chat-based virtual world. He investigated the interactions of non-native-English-speakers in a threedimensional virtual world which incorporated avatars and text chat. Analysis of the chat transcripts indicated the subjects employed both transactional communication strategies and interactional strategies. Further analysis showed that instances of negotiation of meaning focused on lexis all the time. 
Different task types seemed to influence the quantity of negotiation, with more negotiation occurring in the decision-making task than in the jigsaw and opinion-exchange tasks. The analysis further suggested that the use of avatars facilitated learner interaction management during real time CMC. There is other research related to avatars in Second Life as well. Hemp (2006) performed research on marketing strategies used in SL. There, residents ran virtual businesses that sold virtual products in Linden dollars, which could later be converted into real-world currency on various Internet exchanges. Kohler, Matzler, \& Füller's(2009) study explored the opportunities that virtual worlds offer to real-world innovators. By integrating users of virtual worlds into an interactive new product-development process, customers' virtual-world-based innovation could be applied in the real world. In Liou(2012) study titled "The roles of Second Life in a college computer-assisted language learning (CALL) course in Taiwan, ROC", Liou investigated how SL could be infused into a CALL course through task design. Four task-orientation of SL chatting, pedagogical activities, peer review, and an SL tour-were designed by students and analyzed. Although students felt frustrated about the unstable Internet, they confirmed the benefits of using SL for English learning and teaching. Second Life established an authentic environment for communication and provided an abundance of interaction and immersion which were beneficial to the student-participants' English learning. This study is somewhat different from the above research because this study focuses on the use of politeness strategies. Six politeness strategies used by SL residents are analyzed in this study: Direct Command, Positive Politeness, Negative Politeness, Pre-Request, Off Record, and Bald on Record. The purpose of this study was to investigate how often Taiwanese English students and the non-Taiwanese English speakers they communicated with in SL made use of politeness strategies in their conversations and how speech-act performance could be taught through the suggestions of experts to help enhance the English learners' pragmatic acquisition of English. Therefore, my research questions were as follows:

(a) How often did learners and foreigners make use of politeness strategies (Direct Command/Positive Politeness/Negative Politeness/Pre-Request/Off-Record/Bald on Record) in avatars and chat-based Second Life virtual world?

(b) How speech act performance could be learnt through the suggestion of experts to help enhance the learners' pragmatic acquisition?

\section{Method}

\subsection{Participants}

The total number of participants was 240 . This number consists of 50 Taiwanese University nursing students and 190 non-Taiwanese English speakers to whom they spoke in SL. Each student was required to participate in SL and talk online with no more than five foreign native English speakers of their own choosing. Any topic could be discussed during their conversations. The 50 Taiwanese participants in this study were junior nursing students who attended the nigh-school division and worked in the daytime. They had studied English for more than four years; however, their level of English proficiency was still no higher than the Elementary Level of the General English Proficiency Test (GEPT) because although they had all taken the Elementary Level GEPT test, none of them has passed it. The study was based on an assignment given to students who wanted to boost their grades in their English reading course. The participants were not provided with any substantial help, such as the useful vocabulary words or sentences, nor were they given any information related to politeness strategies. However, they were taught how to register in SL.

\subsection{Instruments}

The instruments used in this study included online transcripts and a computer. The transcripts were read and analyzed, and the computer was used for statistical analysis.

\subsection{Procedure}

This project was conducted for the duration of one semester. In the orientation phase, the learners were taught how to register in Second Life, how to choose an avatar, and how to find native English speakers on line. The subjects were allowed to self-select any avatar they wanted after they had entered the virtual environment and they were also allowed to change any avatar as they liked at any time, no matter whether it was a female, a male, a car, a robot, an animal or a vampire. The subjects were allowed to go anywhere in the SL world. Following their SL interactions, the researcher collected the transcripts from the students, read the transcripts, identified the requests, and classified the politeness strategies from the transcripts into Positive Politeness Strategy, Negative Politeness Strategy, Direct Command, Pre-Request, Off Record or Bald on Record. 


\section{Discussion and Conclusion}

Analysis of the politeness strategies contained in the transcripts reveals that, though none of the Taiwanese students had ever received any training in politeness strategies, they utilized most of them. The Taiwanese students showed a higher frequency of politeness strategies in their communication than the non-Taiwanese English speakers did, so we can assume that the politeness strategies are more important to the Taiwanese students than to non-Taiwanese. Based on the data, the most frequently applied politeness strategy for requests was a Direct Command (73.78\%), with $37.28 \%$ of native speakers using it, and $36.50 \%$ of Taiwanese students utilizing it. It seems that in the Second Life virtual world, people frequently use a more direct approach to get the information that they want, and they treat each other with a high degree of familiarity and don't worry about others losing face when they use the Direct Command strategy. From the analysis, it seemed like the foreigners were more open-minded and would like to treat everyone like friends and that is why they would use more direct command than those of the local students.

The second-most frequently used politeness strategy in making requests was Positive Politeness (15.90\%), with $7.30 \%$ of non-Taiwanese utilizing it and $8.50 \%$ of Taiwanese students. Based on these numbers, it seems that Taiwanese students were willing to appeal to friendship more often than their online partners. Taiwanese students used words and terms such as "we" and "let's" more often to emphasize their closeness and solidarity with the non-Taiwanese SL residents.

The third-most commonly applied politeness strategy for requests was Negative Politeness (6.01\%), with $2.71 \%$ of non-Taiwanese utilizing it and 3.3\% of Taiwanese. In order to prevent themselves from receiving facethreatening acts or from bringing imposition upon others, local students used the Negative Politeness strategy more frequently than the foreigners. The tendency to use Negative Politeness referred to that the listeners had the right to freedom, which meant that they were independent to receive the invitation or they had the right to refuse it. Based on the statistics, the students in Taiwan seemed to be more afraid to be rejected and lose their face, so they were more inclined to offer their non-Taiwanese counterparts the opportunity to exercise their freedom to accept or reject a request.

The politeness strategy used fourth-most for requests was Off Record (3.4\%), with $1.7 \%$ for both non-Taiwanese and Taiwanese participants. It seems that Taiwanese students and non-Taiwanese counterparts were inclined to use this strategy in equal numbers, which implied that they both were good at giving hints on how to stop their conversation.

The politeness strategy used fifth-most was Pre-Request $(0.77 \%)$, with $0.27 \%$ of non-Taiwanese using it and $0.5 \%$ of Taiwanese students. Apparently, in order to prevent themselves from losing face, the Taiwanese students used the Pre-Request strategy more than the non-Taiwanese students did.

The last politeness strategy for making requests that was analyzed was Bald on Record. Neither Taiwanese nor non-Taiwanese used this strategy even once. It seems clear that both the Taiwanese students and the nonTaiwanese counterparts universally felt that Bald on Record would bring a threat to the other's face, and using such a strategy would shock or embarrass the addressee and that's why both of them would try to skip Bald on Record.

In sum, both the foreigners and the local students did utilize politeness strategies even though they probably had not received any direct training in them. The Taiwanese students seemed to be more afraid to receive facethreatening acts than the non-Taiwanese, so they used more strategies like Positive Politeness, Negative Politeness, and Pre-Request. The non-Taiwanese seemed to be less concerned about losing face and used the Direct Command method more frequently so as to treat the Taiwanese students as their friends. Both the foreigners and local students knew the strategy Off Record very well, and they knew how to skillfully stop their conversation with a polite strategy. Likewise, both the foreigners and local students knew that Bald- on-Record strategy would bring menace to the other person's face and could be utilized only in situation where the speaker had a very intimate relationship with the listener. Thus, they chose not to use that strategy in order to prevent themselves from bring threats to other. 
Table I. Summary of politeness strategies used in avatars and chat-based virtual world

\begin{tabular}{llll} 
Politeness Strategy & Foreigners & Students & Total \\
\hline 1.Direct Command & 37.28 & 36.50 & 73.78 \\
2.Positive Politeness & 7.30 & 8.50 & 15.80 \\
3.Negative Politeness & 2.71 & 3.30 & 6.01 \\
4.Pre-Request & 0.27 & 0.50 & 0.77 \\
5.Off Record & 1.70 & 1.70 & 3.40 \\
6.Bald On Record & 0.00 & 0.00 & 0.00 \\
\hline Total & 49.26 & 50.05 & 99.76
\end{tabular}

\section{Pragmatic Acquisition}

From the above analysis, it seemed that the both the non-Taiwanese counterparts and local students were somewhat good at politeness strategies even though they had not been taught the strategies before. However, based on the following studies, politeness strategies could be taught via certain instruction in class.

As to the research question of how speech-act performance could be learned through the suggestions of experts to help enhance the learners' pragmatic English acquisition, what we need to strengthen is not only linguistic competence but also sociolinguistic competence. Based on Canale and Swain(1980), although linguistic competence is essential for developing proficiency, we also needed to develop students' sociolinguistic, discourse, and strategic competence; therefore, teachers should provide students with "the information, practice, and much of the experience needed to meet their communicative needs in the second language" (p. 28). Because pragmatics entails both performing communicative acts and social perceptions of these acts, teaching materials should involve several key elements: social context, functional language use, and interaction. Thus, activities and tasks should be designed to incorporate these components (Canale \& Swain, 1980).Pragmatics teaching can be performed in traditional or nontraditional learning contexts. Traditional learning context refers to pragmatics that can be taught in class. According to Lei, Qinghui, and Zheqing ( 2014), speech acts can be introduced through teaching materials related to pragmatics (p.21). Another teaching method, such as a task-based approach, could be applied to pragmatics as well. The teacher can give learners a task that contains both appropriate and inappropriate speech acts that students can discus and then make a report in class. Such a discussion can raise learners' awareness of speech acts and provide them with a better cross-cultural communication experience. Another way to improve learners' communicative competence, according to Lei (2014, p. 22), is through reading. The teacher should encourage the learners to read between the lines and try to make them understand the sarcasm or irony behind the lessons.

Nontraditional learning context refers to pragmatics that could be taught via technology. There are several websites dedicated to L2 pragmatics that help English-learners use socially appropriate language in a variety of formal and informal situations. Other pragmatic materials that provide real and abundant language are TV programs and films. Students can be asked to identify speech acts in the video and then to practice the speech acts through role-playing (Peterson, 2006). Synchronous and asynchronous computer-mediated communication (CMC) is another available tool for pragmatics learning. CMC offers learners an authentic context for communication by engaging them in online dialogues with foreign partners.

No matter whether the speech acts are taught in traditional or nontraditional learning contexts, they should follow the following five steps in order to enhance pragmatic acquisition. Olshtain and Cohen (1991) suggested five steps for presenting and practicing speech acts: diagnostic assessment, model dialogue, evaluation of the situation, role - play activities, and feedback and discussion. Diagnostic assessment allows the teacher to establish the students' level of awareness of speech acts and to concentrate on their weak parts to be taught, so it is important for the teacher to provide rich exposure of speech acts for the learners. Teachers can then present students with model dialogues, followed by situational evaluation to practice learners' awareness of the speech acts they have just been involved in. The fourth step is role-playing activities for learners to practice and produce what they have just learned as to make sure they had fully understood each pattern of speech act. Finally, we should have feedback and discussion to investigate if there are other inappropriate speech acts that need to be amended. 
By analyzing politeness strategies (Direct Commend/Positive Politeness/Negative Politeness/Pre-Request/Off Record/Bald On Record), learners can understand more about how to be polite when engaging in communication, especially in making requests, because it helps the learners to choose the sentences and words that will help prevent them from receiving face-threatening acts when they communicate with others. A linguistic interaction is actually a social interaction and we have to make good use of politeness strategies in order to facilitate the understanding between speakers and listeners. Speech act related politeness should be taught as well in order to help enhance learners' pragmatic acquisition. Speech acts related politeness can be taught in class via traditional or nontraditional learning context. Traditional ways of teaching speech acts include using textbooks about politeness, devising tasks and activities concerning politeness, and reading books about politeness. Nontraditional ways of teaching speech acts include providing websites, TV shows, and films related to politeness, or role playing the lessons that have been taught concerning politeness. The five steps to enhance learners' pragmatic acquisition should consist of diagnostic assessment, model dialogue, evaluation of the situation, role playing activities, and feedback and discussion. It is firmly believed that by way of mastering traditional or nontraditional learning contexts, speech acts among learners will be improved some day or later.

\section{References}

Canale, M., \& Swain, M. (1980). Theoretical bases of com-municative approaches to second language teaching and testing. Applied Linguistics, 1(1), 1-47.

Goffman, E. (1955). On face-work: An analysis of ritual elements in social interaction. Psychiatry, 18(3), 213-231. Hemp, P. (2006).Avatar-based marketing.Harvard Business Review, 84(6), 48-57.

Hiltz, S. R., \&Turoff, M. (1993). The network nation: Human communication via computer: Mit Press.

Hymes, D. (1967). Models of the interaction of language and social setting.Journal of Social Issues, 23(2), 8-28.

Ide, S. (2005). How and Why honorifics can signify dignity and elegance: The Indexicality and Reflexivity of Linguistic Rituals. Broadening the Horizaon of Linguistic Politeness, 139, 45-64.

Kohler, T., Matzler, K., \&Füller, J. J. T. (2009). Avatar-based innovation: Using virtual worlds for real-world innovation. Elsevier, 29(6-7), 395-407.

Lei, C., Qinghui, Z., \&Zheqing, L. (2014).Speech Act Theory and Its Implications to English Teachers.Education and Social Science, January, 19-22.

Levinson, P., Brown, P., Levinson, S. C., \& Levinson, S. C. (1987).Politeness: Some universals in language usage (Vol. 4): Cambridge university press.

Liou, H.-C. (2012). The roles of Second Life in a college computer-assisted language learning (CALL) course in Taiwan, ROC. Computer Assisted Language Learning, 25(4), 365-382.

Olshtain, E., \& Cohen, A. (1991).Teaching speech act behavior to nonnative speakers.Teaching Englih as a Second or Foreign Language, 2, 154-165.

Pearson, L. (2006). Patterns of development in Spanish L2 pragmatic acquisition: An analysis of novice learners' production of directives. Modern Language Journal, 90(4), 473-495.

Peterson, M. (2006).Learner interaction management in an avatar and chat-based virtual world.Computer Assisted Language Learning, 19(1), 79-103.

Song, S. (2012). Politeness and culture in second language acquisition: Palgrave Macmillan.

TolmachLakoff, R. (1990). Talking Power, The Politics of language in Our Lives. In: Basik Books, Harper Collins Publishers, New York.

Ukosakul, M. (2005).The significance of 'face'and politeness in social interaction as revealed through Thai 'face'idioms.Broadening the Horizon of linguistic Politeness, 139, 117-125.

Watts, R. J. (2003). Politeness: Cambridge University Press.

Winerta, V., \&Hamzah, R. A. S. (2012). An Analysis of Politeness Strategies in Requesting Used in Real Human and Non-Human Conversation on "Avatar" Movie. English Department Faculty of Language and Art, $1(1), 1-12$.

Yule, G. (1997). Pragmatics. Oxford: Oxford University Press. 